\title{
Vacuum Residue Upgrading Via Catalytic Steam Cracking in Slurry Type Reactor in Presence of Mo-based Dispersed Catalyst
}

\author{
Gleb A. Sosnin*a,b, Olesya O. Zaikina ${ }^{\mathrm{a}, \mathrm{b}}$, \\ Peter M. Eletskii ${ }^{a}$ and Vadim A. Yakovlev ${ }^{a, b}$ \\ ${ }^{a}$ Boreskov Institute of Catalysis $S B R A S$ \\ 5 Lavrentiev, Novosibirsk, 630090, Russia \\ ${ }^{b}$ Novosibirsk State University \\ 2 Pirogova Str., Novosibirsk, 630090, Russia
}

The catalytic steam cracking of vacuum residue (VR) in a slurry-type reactor at a temperature of $425-450{ }^{\circ} \mathrm{C}$ and $2 \mathrm{MPa}$ in the presence of a Mo-based dispersed catalyst was carried out for the first time. The catalyst was introduced into the feedstock through a reverse emulsion, which was previously prepared from VR and an aqueous solution of the Mo-based precursor salt, followed by decomposition and formation of a dispersion of catalyst particles in the VR. In the case of non-catalytic steam cracking, it was found that the use of water leads to a reduction in coke formation and, correspondingly, an increase in the yield of the target liquid products (semisynthetic oil), while reducing the sulfur content, in comparison with thermal cracking. The results of the study also showed that the use of Mo-based dispersed catalyst increases the depth of interaction between water and VR, with an increase in the $H: C$ ratio and a reduction in sulfur content in liquid products (semisynthetic oil).

Keywords: heavy oil, vacuum residue, dispersed catalyst, catalytic steam cracking, thermal cracking, molybdenum, slurry-reactor.

Citation: Sosnin G.A., Zaikina O.O., Eletskii P.M., Yakovlev V.A. Vacuum residue upgrading via catalytic steam cracking in slurry type reactor in presence of Mo-based dispersed catalyst, J. Sib. Fed. Univ. Chem., 2018, 11(3), 447-456. DOI: $10.17516 / 1998-2836-0090$.

(C) Siberian Federal University. All rights reserved

* Corresponding author E-mail address: sosningleb@catalysis.ru 


\title{
Исследование процесса каталитического \\ парового крекинга гудрона в реакторе типа сларри \\ в присутствии дисперсного катализатора \\ на основе молибдена
}

\author{
Г.А. Соснин ${ }^{\mathrm{a}, \tilde{\sigma}}$, O.O. Заикина ${ }^{\mathrm{a}, \tilde{\sigma}}$, \\ П.М. Елецкий ${ }^{\mathrm{a}}$, В.А. Яковлев ${ }^{\mathrm{a}, \mathrm{\sigma}}$ \\ ${ }^{a}$ Институт катализа им. Г.К. Борескова СО РАН \\ Россия, 630090, Новосибирск, пр. Академика Лаврентьева, 5 \\ ${ }^{6}$ Новосибирский государственный университет \\ Россия, 630090, Новосибирск, ул. Пирогова, 2
}

Впервые проведено исследование каталитического парового крекинга гудрона в проточном реакторе типа сларри при температуре $425-450{ }^{\circ} \mathrm{C}$ и давлении 2 МПа в присутствии Мосодержащего дисперсного катализатора. Катализатор вводили в сырье через стадию образования обратной эмульсии, которую предварительно получали из гудрона и водного раствора Мо-содержащей соли-прекурсора, с ее последующим разложением и образованием дисперсии частии катализатора в гудроне. В случае некаталитического парового крекинга было обнаружено, что использование воды приводит к снижению коксообразования $u$, соответственно, увеличению выхода целевых жидких продуктов (полусинтетической нефти) с одновременным снижением содержания серы в последних по сравнению с термическим крекингом. Результаты исследования также показали, что применение Мо-содержащего дисперсного катализатора позволяет увеличить глубину взаимодействия воды и гудрона с повышением соотношения H/C и снижением содержания серы в жидких продуктах (полусинтетической нефти).

Ключевые слова: тяжелое нефтяное сырье, гудрон, дисперсный катализатор, паровой крекинг, термический крекинг, молибден, сларри-реактор.

\section{Введение}

По прогнозам экспертов, ввиду неуклонного роста энергопотребления в мире ожидается, что в ближайшие два десятилетия данный параметр увеличится более чем на 50 \%. Однако, несмотря на существенный вклад альтернативных и возобновляемых источников в мировую структуру энергопотребления, одним из основных источников энергии по-прежнему остается ископаемое углеводородное сырье [1, 2]. Вышеуказанные тенденции, а также истощение запасов легких и средних нефтей, обуславливают необходимость вовлечения в структуру нефтепереработки нетрадиционных углеводородных ресурсов (тяжелые нефти, битумы, нефтяные сланцы и др.). По различным оценкам на нетрадиционное (тяжелое) сырье приходится от 70 до 80 \% от общего объема разведанных запасов нефтяного сырья [3]. 
Его специфические свойства - высокая вязкость, высокое содержание высокомолекулярных соединений, гетероатомов и металлов и, напротив, низкое содержание водорода - затрудняют переработку тяжелого нефтяного сырья (ТHC) в ценные продукты ввиду низкого выхода светлых фракций и дезактивации катализатора, в основном вследствие отложений металлов и коксообразования [4].

Облагораживание ТНС с получением полусинтетической нефти (ПСН) осуществляют с применением подходов, основанных на снижении содержания углерода в сырье (деасфальтизация [5], замедленное коксование [6], висбрекинг [7] и FCC [8]), насыщении его водородом (гидрогенизационные процессы) либо в их различных сочетаниях [9-11].

Недостаточная селективность по светлым фракциям, низкое качество жидких и высокий выход нежелательных продуктов в случае первого типа процессов, а также высокая стоимость гидрогенизационных подходов являются основными факторами, стимулирующими создание и развитие новых направлений в области переработки ТНС. Данные подходы должны обладать пониженным либо нулевым потреблением дополнительно подаваемого водорода (т.е. так называемые безводородные), но по совокупности характеристик при этом должны превосходить процессы, основанные на снижении содержания углерода в сырье. Одним из таких перспективных подходов является каталитический паровой крекинг - подход по облагораживанию нетрадиционного нефтяного сырья в присутствии водяного пара $[12,13]$.

По своей эффективности каталитический паровой крекинг (КПК) занимает промежуточное положение между процессами, основанными на снижении содержания углерода в сырье и гидропроцессами. Применение воды как в форме водяного пара, так и сверхкритического флюида способствует подавлению коксообразования, увеличению конверсии высококипящих фракций и насыщению сырья водородом [14-17].

В последнее время для переработки ТНС исследователи все больше прибегают к использованию дисперсных катализаторов $[18,19]$. Преимуществом данного типа катализаторов является отсутствие пористой структуры в отличие от традиционных нанесенных гетерогенных катализаторов. Это приводит к отсутствию диффузионных затруднений массопереноса и большей доступности высокодисперсных активных центров для крупных молекул ТНС (например, асфальтенов) и углеводородных радикалов, что способствует подавлению их поликонденсации [20].

Дисперсные катализаторы на основе молибдена находят применение в процессах гидропереработки тяжелой нефти [20, 21], гудрона [22, 23], благодаря их высокой эффективности в процессе глубокой гидроочистки сырья с выделением сероводорода, который далее используется для производства серной кислоты. Получение Мо-содержащих дисперсных катализаторов insitu позволяет частично применять серу, содержащуюся в сырье в качестве сульфидирующего агента, что, в свою очередь, также снижает содержание серы в продуктах облагораживания.

Молибден также входит в состав активных компонентов катализаторов, используемых в процессах гидрооблагораживания (гидрокрекинга, гидрообработки), в том числе и тяжелых остатков нефтепереработки (гудронов, мазутов) [23, 24].

Вследствие этого исследование активности дисперсных катализаторов на основе молибдена в процессе каталитического парового крекинга гудрона представляет собой не только фундаментальный интерес, но и практическую значимость.

$$
-449-
$$


Целью данной работы является изучение особенностей процесса каталитического парового крекинга гудрона в присутствии 0,5 мас. \% Мо-содержащего дисперсного катализатора. Для сравнения были проведены эксперименты по термическому, паровому и каталитическому паровому крекингу гудрона при 425 и $450{ }^{\circ} \mathrm{C}$.

\section{Экспериментальная часть}

Свойства используемого гудрона

В экспериментах использовали гудрон западно-сибирской нефти АО Газпромнефть-ОНПЗ с высоким содержанием серы (1,8 мас. \%), состоящий из углеводородных фракций с температурой кипения выше $500{ }^{\circ} \mathrm{C}$. В табл. 1 представлены данные по CHNS-составу, плотности, вязкости и коксуемости по Конрадсону.

\section{Методика приготовления катализатора}

Используемый в экспериментах Мо-содержащий дисперсный катализатор формировался in-situ в горячей зоне реактора из приготовленной ранее обратной эмульсии. Методика приготовления обратной эмульсии заключается в равномерном диспергировании соответствующего количества водного раствора предшественника катализатора (парамолибдат аммония) в нагретом до $80{ }^{\circ} \mathrm{C}$ гудроне. Количество воды и парамолибдата аммония отбирали таким образом, чтобы в состав конечной эмульсии входило 10 \% воды и 0,5 \% Мо в пересчете на металл. Диспергирование осуществляли с использованием диспергатора IKA T-25 basic ULTRA-TURRAX при скорости перемешивания 24000 об/мин в течение 3 мин.

\section{Методика проведения эксперимента}

Исследование каталитического парового крекинга гудрона проводили на установке с проточным реактором типа сларри (рис. 1) при температуре $425-450{ }^{\circ} \mathrm{C}$ и давлении 2,0 МПа. Внутренний диаметр реактора - 20 мм, длина - 300 мм, материал - нержавеющая сталь.

Подача обратной эмульсии водного раствора предшественника в реактор обеспечивается с помощью поршня, подогреваемого до $60{ }^{\circ} \mathrm{C}$. Скорость подачи сырья составляла 100 мл/ч

Таблица 1. Основные характеристики использованного в экспериментах гудрона

Table 1. The main characteristics of the vacuum residue used in the experiments

\begin{tabular}{|c|c|}
\hline Элементный состав & Содержание, мас. \% \\
\hline $\mathrm{C}$ & 86,3 \\
\hline $\mathrm{H}$ & 11,3 \\
\hline $\mathrm{N}$ & 0,9 \\
\hline $\mathrm{S}$ & 1,8 \\
\hline Атомное соотношение $\mathrm{H}: \mathrm{C}$ & 1,57 \\
\hline Плотность при $25^{\circ} \mathrm{C}, \mathrm{\Gamma}_{\mathrm{cm}}{ }^{3}$ & 1,00 \\
\hline Кинематическая вязкость при $60^{\circ} \mathrm{C}, \mathrm{Mm}^{2} / \mathrm{c}$ & 6712,5 \\
\hline Коксуемость по Конрадсону, мас. $\%$ & 19,6 \\
\hline
\end{tabular}




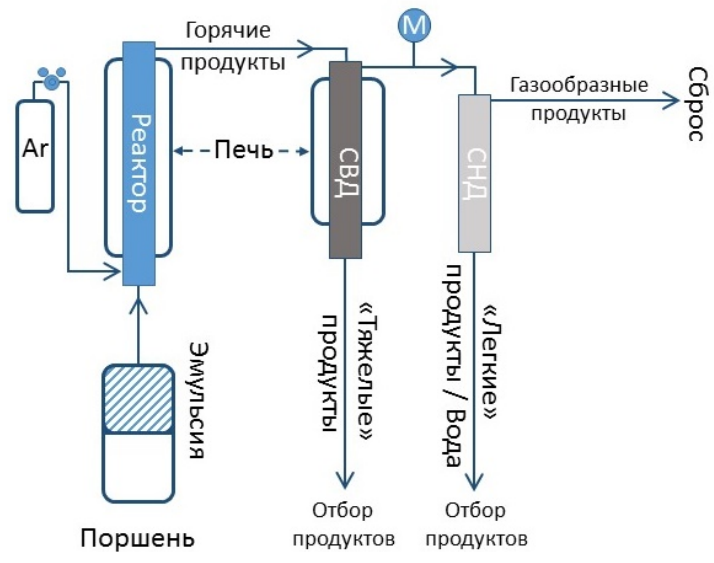

Рис. 1. Схема проточной установки с реактором типа сларри для проведения экспериментов по каталитическому паровому крекингу гудрона

Fig. 1. Scheme of a flow installation with slurry-type reactor for experiments on catalytic steam cracking of vacuum residue

(в случае термического крекинга - чистого гудрона, в случае парового крекинга - обратной эмульсии воды в гудроне). В реактор также подавали аргон для достижения давления в системе 2,0 МПа со скоростью 100 мл/мин. «Тяжелые» продукты накапливались в сепараторе высокого давления (СВД), нагретого до $230{ }^{\circ} \mathrm{C}$, более «легкие» продукты и вода далее поступали в сепаратор низкого давления (СНД), охлаждаемого до комнатной температуры. Жидкие продукты крекинга после отделения воды объединяли и анализировали. Определение выхода продуктов уплотнения проводили путем суммирования массы остатков в реакторе, после отмывки дихлорметаном, с содержанием кокса в жидких продуктах, которое определяли следующим образом. Часть жидких продуктов растворяли в избытке дихлорметана с последующим центрифугированием и промыванием остатка на бумажном фильтре.

Продукты переработки гудрона исследовали следующими физико-химическими методами:

\section{HCNS-O анализ жидких продуктов переработки гудрона}

Элементный CHNS-состав жидких образцов определяли на CHNS-O-анализаторе VARIO EL CUBE (Elementar Analysen systeme, Германия). Пробу анализировали не менее трех раз с последующим усреднением полученных данных.

\section{Определение фракционного состава жидких нефтепродуктов по ASTM D7169-11}

Фракционный состав исходного гудрона и объединенных жидких продуктов его переработки определяли с помощью высокотемпературной газовой хроматографии в соответствии со стандартом ASTM D7169-11. В качестве стандартного вещества для определения степени извлечения использовали вакуумный газойль.

\section{Определение кинематической вязкости}

Кинематическую вязкость измеряли исходя из величин, плотности и динамической вязкости, определенных на вискозиметре Штабингера по стандарту ASTM D7042. Кинемати- 
ческую вязкость измеряли в диапазоне температур $20-100{ }^{\circ} \mathrm{C}$ в зависимости от исследуемого образца.

\section{Определение плотности}

Определение плотности исходного углеводородного сырья и продуктов переработки проводили на вискозиметре Штабингера по стандарту ASTM D7042.

\section{Результаты и обсуждения}

Оценку эффективности термического (ТК), парового (ПК) и каталитического парового (КПК) крекинга гудрона проводили по совокупности таких параметров, как выход фракций с температурой кипения менее $500{ }^{\circ} \mathrm{C}$, а также выход полусинтетической нефти (ПСН), образование побочных продуктов (кокс и газообразные продукты), содержание серы и соотношение Н/С в жидких продуктах и некоторых других (табл. 2).

Было установлено, что повышение температуры термического крекинга приводит к увеличению конверсии гудрона, но это увеличение протекает, в основном, за счет диспропорционирования сырья до легких фракций (в т.ч. газообразных продуктов) и продуктов уплотнения, т.е. наблюдалась малая селективность по целевым продуктам, что объясняет низкий выход ПСН. Однако при введении 10 мас. \% воды в систему (ПК) выхода кокса снизился, вероятнее всего, из-за гашения предшественников коксообразования - углеводородных радикалов с вы-

Таблица 2. Выход, состав и свойства продуктов термического, парового и каталитического парового крекинга гудрона при 425 и $450{ }^{\circ} \mathrm{C}$. Условия процесса: давление - 2 МПа, объемная скорость подачи гудрона $-0,1$ л/ч

Table 2. Yield, composition and properties of products of thermal, steam and catalytic steam cracking of vacuum residue at 425 and $450{ }^{\circ} \mathrm{C}$. Process conditions: pressure $-2 \mathrm{MPa}$, volumetric feed rate of vacuum residue $-0.1 \mathrm{~L} / \mathrm{h}$

\begin{tabular}{|c|c|c|c|c|c|c|c|}
\hline \multirow{2}{*}{ Выход фракций, мас. \% } & \multirow{2}{*}{$\begin{array}{c}\text { Исходный } \\
\text { гудрон }\end{array}$} & \multicolumn{2}{|c|}{$\mathrm{TK}^{1}$} & \multicolumn{2}{|c|}{$\Pi K^{2}$} & \multicolumn{2}{|c|}{ КПК ${ }^{3}$ Мо 0,5 мас. \% } \\
\hline & & $425^{\circ} \mathrm{C}$ & $450{ }^{\circ} \mathrm{C}$ & $425^{\circ} \mathrm{C}$ & $450{ }^{\circ} \mathrm{C}$ & $425^{\circ} \mathrm{C}$ & $450{ }^{\circ} \mathrm{C}$ \\
\hline Газообразные прод. & - & 4,2 & 10,1 & 4,1 & 5,5 & 4,5 & 5,8 \\
\hline Бензиновая & 0 & 4,3 & 16,6 & 5,9 & 8,4 & 6,1 & 10,5 \\
\hline Дизельная & 0 & 10,9 & 21,6 & 11,1 & 12,5 & 13,2 & 10,7 \\
\hline Масляная & 5 & 13,6 & 12,2 & 11,1 & 15,1 & 13,2 & 14,7 \\
\hline Остаточная & 95 & 57,7 & 16,9 & 57,6 & 49,2 & 55,5 & 50,8 \\
\hline Кокс ${ }^{4}$ & - & 4,3 & 15,5 & 2,0 & 3,1 & 2,3 & 2,9 \\
\hline Светлые & 0 & 15,2 & 38,2 & 17,0 & 20,9 & 19,3 & 21,2 \\
\hline Выход ПСН & - & 85,0 & 65,8 & 90,0 & 85,2 & 88,0 & 86,7 \\
\hline Потери & - & 6,5 & 8,6 & 3,9 & 6,2 & 5,2 & 4,6 \\
\hline $\mathrm{H} / \mathrm{C}$ в ПСН & 1,57 & 1,45 & 1,63 & 1,48 & 1,50 & 1,52 & 1,56 \\
\hline Содержание S в ПСН & 1,80 & 1,63 & 1,23 & 1,55 & 1,32 & 1,45 & 1,27 \\
\hline 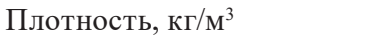 & 1000 & 954 & 890 & 950 & 935 & 937 & 941 \\
\hline Вязкость, сСт $\left(60^{\circ} \mathrm{C}\right)$ & 6712,5 & 193 & 52 & 187 & 125 & 182 & 83 \\
\hline
\end{tabular}

Примечание: ${ }^{1}$ - Термический крекинг. ${ }^{2}$ - Паровой крекинг без катализатора. ${ }^{3}-$ Каталитический паровой крекинг.

${ }^{4}$ - Выход кокса с учетом зольности. ${ }^{5}$ - Выход полусинтетической нефти (жидких продуктов). 
сокой молекулярной массой, образующихся в том числе из асфальтенов. Об этом также свидетельствует повышение соотношения Н/C в жидких продуктах. Данные факты согласуются с результатами, полученными в экспериментах с тяжелой татарской нефтью с использованием автоклавного реактора [14].

Увеличение температуры процесса ПК привело к увеличению глубины обессеривания и выхода светлых фракций в ПСН как за счет термических процессов, так и, возможно, за счет взаимодействия воды и сырья, о чем свидетельствует увеличение соотношения Н/C в жидких продуктах и степени обессеривания. Тем не менее выход кокса также увеличился за счет более интенсивных процессов крекинга углеводородов с последующей конденсацией высокомолекулярных ароматических радикалов.

Использование Мо-содержащего дисперсного катализатора позволяет интенсифицировать процессы взаимодействия воды и гудрона. Подробные исследования Мо-содержащего дисперсного катализатора, образующегося in-situ при облагораживании тяжелой нефти в автоклавном реакторе, представлены в $[14,25]$. В среде углеводородного сырья и водяного пара, по данным ПЭМ, прекурсор Мо-содержащего дисперсного катализатора - парамолибдат аммония превращается в хорошо окристаллизованные частицы и агломераты $\mathrm{MoO}_{2}$ с размерами менее 100 нм и 1-2-слойные пластинчатые частицы $\mathrm{MoS}_{2}$ протяженностью 10-15 нм. Было показано [14], что его использование приводит к интенсификации процессов взаимодействия воды и углеводородов ТНС по механизму парциального парового риформинга (рис. $2 a$ ) и обессеривания (рис. 2б).

Было установлено, что процесс каталитического парового крекинга позволяет уменьшить исходную вязкость гудрона в 40 раз при $425{ }^{\circ} \mathrm{C}$ и в $\sim 80$ раз при $450{ }^{\circ} \mathrm{C}$, однако схожие значения достигаются и в случае термического и парового крекинга без катализатора, т.е. при данных условиях определяются термическими эффектами.

Таким образом, применение катализатора на основе Мо в процессе облагораживания приводит к получению ПСН, обладающих более высоким соотношением Н/С и меньшим содержа-

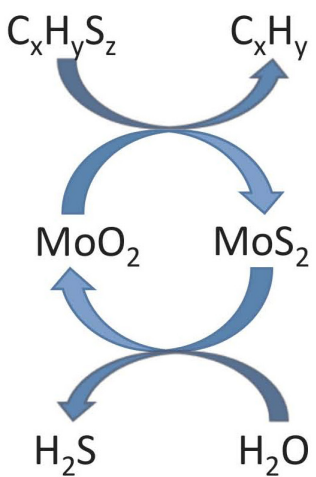

a

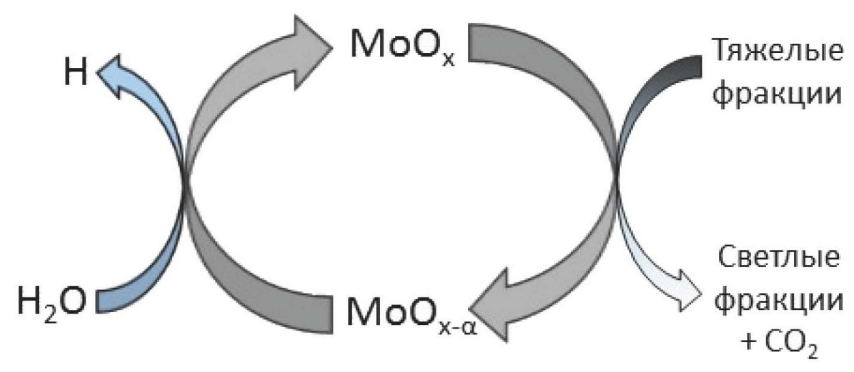

б

Рис. 2. Предполагаемая схема каталитического обессеривания (а) и парциального парового риформинга (б) Мо-содержащих дисперсных катализаторов в процессе каталитического парового крекинга тяжелого нефтяного сырья

Fig. 2. Assumed scheme for catalytic desulfurization (a) and partial steam reforming (б) on Mo-based dispersed catalysts in the process of catalytic steam cracking of heavy oil feedstocks

$$
-453 \text { - }
$$


нием серы по сравнению с термическим и паровым крекингом без катализатора. Образование водорода in-situ позволяет снизить выход коксовых отложений и увеличить выход ценных светлых фракций.

Таким образом, по совокупности выбранных параметров каталитический паровой крекинг в присутствии Мо-содержащих дисперсных катализаторов превосходит паровой крекинг без катализатора и термический крекинг при прочих равных условиях эксперимента.

\section{Заключение}

В работе впервые проведено исследование процесса парового крекинга гудрона в проточном режиме в реакторе типа сларри в присутствии Мо-содержащего дисперсного катализатора, формирующегося из обратной эмульсии in-situ. Было установлено, что введение воды в процесс приводит к снижению выхода кокса, что в свою очередь способствует увеличению конверсии гудрона в полусинтетическую нефть с одновременным снижением содержания в ней серы. Использование дисперсного катализатора на основе молибдена позволяет снизить выход продуктов уплотнения и содержание серы в жидких продуктах. Вязкость полусинтетической нефти, полученной из гудрона, падает в $40-80$ раз по отношению к исходному сырью. Данный показатель не уступает аналогичному, полученному в ходе термического крекинга. Таким образом, можно заключить, что каталитический паровой крекинг является альтернативой процессам, основанным на снижении содержания углерода в сырье, поскольку снижает вклад коксообразования в конверсию гудрона, что в свою очередь влияет и на экономический аспект данной технологии.

\section{Благодарности}

Работа выполнена при финансовой поддержке Министерства науки и высшего образования Российской Федерации: соглашение № 14.607.21.0172, идентификационный номер соглашения RFMEFI60717X0172, название «Разработка новых технологических решений облагораживания углеводородного сырья, минимизирующих или исключающих образование отходов и негативного воздействия на окружающую среду».

\section{Список литературы}

1. International Energy Outlook. U.S. Energy Information Administration 2016. P. Vol. 0484. https://www.eia.gov/outlooks/ieo/pdf/0484 \%282016 \%29.pdf (accessed September 10, 2018).

2. Alaei M., Bazmi M., Rashidi A, Rahimi A. Heavy crude oil upgrading using homogenous nanocatalyst. Journal of Petroleum Science and Engineering 2017. Vol. 158, P. 47-55.

3. Alboudwarej H., Felix J., Taylor S., Badry R., Bremner C., Brough B., Skeates C., Baker A., Palmer D., Pattison K., Beshry M., Krawchuk P., Brown G., Calvo R., Triana J. a C., Hathcock R., Koerner K., Hughes T., Kundu D., De Cárdenas J.L., West C. Highlighting heavy oil. Oilfield Review 2006. Vol. 18 (2), P. 34-53.

4. Arcelus-Arrillaga P., Pinilla J.L., Hellgardt K., Millan M. Application of Water in Hydrothermal Conditions for Upgrading Heavy Oils: A Review. Energy and Fuels 2017. Vol. 31 (5), P. 4571-4587.

5. Ng S.H. Nonconventional Residuum Upgrading by Solvent Deasphalting and Fluid Catalytic Cracking. Energy \& Fuels 1997. Vol. 11 (6), P. 1127-1136. 
6. Sawarkar A.N., Pandit A.B., Samant S.D., Joshi J.B. Petroleum residue upgrading via delayed coking: A review. Canadian Journal of Chemical Engineering 2007. Vol. 85 (1), P. 1-24.

7. Joshi J.B., Pandit A.B., Kataria K.L., Kulkarni R.P., Sawarkar A.N., Tandon D., Ram Y., Kumar M.M. Petroleum residue upgradation via visbreaking: A review. Industrial and Engineering Chemistry Research 2008. Vol. 47 (23), P. 8960-8988.

8. Abul-Hamayel M.A. Atmospheric residue as feedstock to high-severity fluid catalytic cracking. Petroleum Science and Technology 2002. Vol. 20 (5-6), P. 497-506.

9. Li N., Yan B., Xiao X.M. A review of laboratory-scale research on upgrading heavy oil in supercritical water. Energies 2015. Vol. 8 (8), P. 8962-8989.

10. Castañeda L.C., Muñoz J.A.D., Ancheyta J. Current situation of emerging technologies for upgrading of heavy oils. Catalysis Today 2014. Vol. 220-222, P. 248-273.

11. Ancheyta J., Speight J.G. Hydroprocessing of heavy oils and residua, CRC Press, 2007.

12. Shokrlu Y.H., Babadagli T. Viscosity reduction of heavy oil/bitumen using micro- and nanometal particles during aqueous and non-aqueous thermal applications. Journal of Petroleum Science and Engineering 2014. Vol. 119, P. 210-220.

13. Dutta R.P., McCaffrey W.C., Gray M.R., Muehlenbachs K. Thermal Cracking of Athabasca Bitumen: Influence of Steam on Reaction Chemistry. Energy \& Fuels 2000. Vol. 14 (3), P. 671-676.

14. Mironenko O.O., Sosnin G.A., Eletskii P.M., Gulyaeva Y.K., Bulavchenko O.A., Stonkus O.A., Rodina V.O., Yakovlev V.A. A study of the catalytic steam cracking of heavy crude oil in the presence of a dispersed molybdenum-containing catalyst. Petroleum Chemistry 2017. Vol. 57 (7), P. 618-629.

15. Eletskii P.M., Mironenko O.O., Kukushkin R.G., Sosnin G.A., Yakovlev V.A. Catalytic Steam Cracking of Heavy Oil Feedstocks: A Review. Catalysis in Industry 2018. Vol. 10 (3), P. 185-201.

16. Eletskii P.M., Mironenko O.O., Sosnin G.A., Bulavchenko O.A., Stonkus O.A., Yakovlev V.A. Investigating the process of heavy crude oil steam cracking in the presence of dispersed catalysts. II: Investigating the effect of $\mathrm{Ni}$-containing catalyst concentration on the yield and properties of products. Catalysis in Industry 2016. Vol. 8 (4), P. 328-335.

17. Gai X.K., Arano H., Lu P., Mao J.W., Yoneyama Y., Lu C.X., Yang R.Q., Tsubaki N. Catalytic bitumen cracking in sub- and supercritical water. Fuel Processing Technology 2016. Vol. 142, P. 315318.

18. Del Bianco A., Panariti N., Di Carlo S., Elmouchnino J., Fixari B., Le Perchec P. Thermocatalytic hydroconversion of heavy petroleum cuts with dispersed catalyst. Applied Catalysis A, General 1993. Vol. 94 (1), P. 1-16.

19. Zhang S., Liu D., Deng W., Que G. A review of slurry-phase hydrocracking heavy oil technology. Energy and Fuels 2007. Vol. 21 (6), P. 3057-3062.

20. Angeles M.J., Leyva C., Ancheyta J., Ramírez S. A review of experimental procedures for heavy oil hydrocracking with dispersed catalyst. Catalysis Today 2014. Vol. 220-222, P. 274-294.

21. Iwata Y., Araki Y., Honna K., Miki Y., Sato K., Shimada H. Hydrogenation active sites of unsupported molybdenum sulfide catalysts for hydroprocessing heavy oils. Catalysis Today 2001. Vol. 65 (2-4), P. 335-341.

22. Kim S.H., Kim K.D., Lee Y.K. Effects of dispersed MoS2 catalysts and reaction conditions on slurry phase hydrocracking of vacuum residue. Journal of Catalysis 2017. Vol. 347, P. 127-137.

$$
-455-
$$


23. Kadieva M.K., Magomadov E.E., Gusev D.V., Kadiev K.M., Khadzhiev S.N. Activity of a Molybdenum-Containing Composite Nanocatalyst in Vacuum Residue Hydroconversion. Petroleum Chemistry 2017. Vol. 57 (14), P. 1310-1317.

24. Kadiev K.M., Gyul'maliev A.M., Kadieva M.K., Khadzhiev S.N., Batov A.E. QuantumChemical and Experimental Investigation of the Catalytic Activity of Nanosized Particles of NickelPromoted Molybdenum Disulfide in the Hydroconversion Process. Petroleum Chemistry 2018. Vol. 58 (8), P. 638-645.

25. Mironenko O.O., Sosnin G.A., Eletskii P.M., Gulyaeva Y.K., Bulavchenko O.A., Stonkus O.A., Rodina V.O., Yakovlev V.A. Catalytic steam cracking of heavy crude oil with molybdenum and nickel nanodispersed catalysts. Catalysis in Industry 2017. Vol. 9 (3), P. 221-229. 